\title{
Preoperative inhibition of angiotensin-converting enzyme improves systemic and renal haemodynamic changes during aortic abdominal surgery
}

\author{
M. Licker, M. Bednarkiewicz, P. Neidhart, R. Prêtre, M. Montessuit, H. Favre \\ AND D. R. MOREL
}

\begin{abstract}
Summary
We studied 22 patients undergoing aortic surgery, allocated randomly to receive, before induction of anaesthesia, a single i.v. dose of enalapril $50 \mu \mathrm{g}$ $\mathrm{kg}^{-1}$ or saline. During infrarenal aortic crossclamping, we observed similar reductions in oxygen uptake in the two groups, despite greater systemic oxygen delivery in enalapril-treated patients; angiotensin-converting enzyme inhibition prevented the reduction in cardiac output and attenuated the decrease in glomerular filtration. Changes in glomerular filtration secondary to aortic clamping were related positively to changes in renal plasma flow $(r=0.83$ (saline group) and $r=0.65$ (enalapril group)). Creatinine clearance on the first day after operation was significantly higher in the enalapril compared with the saline group. We conclude that enalapril pretreatment is effective in improving systemic oxygen delivery, renal plasma flow and glomerular filtration during aortic abdominal surgery. (Br. J. Anaesth. 1996; 76: 632-639)
\end{abstract}

\section{Key words}

Surgery, vascular. Kidney, blood flow. Kidney, function. Pharmacology, ACE inhibitors.

Major haemodynamic disturbances are often encountered during aortic abdominal surgery. In most instances, infrarenal aortic cross-clamping causes decreases in cardiac output, oxygen delivery and oxygen uptake that are associated with reduced renal blood flow and glomerular filtration rate [1]. After release of the aortic clamp, systemic haemodynamic and metabolic changes revert rapidly to normal, whereas renal function remains impaired, at least temporarily [2].

Although the mechanisms of perioperative renal insufficiency were believed to be related to relative hypovolaemia, decreased myocardial function and increased sympathetic nervous activity, neither fluid volume expansion nor sympathetic block, nor the use of mannitol or dopamine have been shown to attenuate these perioperative changes consistently $[3,4]$. Powerful endogenous vasoconstricting substances such as thromboxane $\mathrm{A}_{2}$, oxygen-derived free radicals and endothelin-1 have been shown to be released during aortic clamping, and all might contribute to prolonged impairment of renal function [5-7]. The importance of the renin-angiotensin system (RAS) has also been emphasized in the regulation of arterial pressure, blood flow distribution and renal function [8]. Experimental evidence suggests that angiotensin II mediates widespread vasoconstriction by causing direct activation of transmembrane calcium transport and indirectly facilitating release of noradrenaline, by sensitizing adrenergic receptors, and also by enhancing the synthesis of thromboxane and endothelin-1 [9]. Clinical investigations have reported increased plasma renin activity (PRA) and angiotensin II concentrations during major surgical procedures, including aortobifemoral bypass $[10,11]$, suggesting that angiotensin II may account to some extent for perioperative circulatory and renal haemodynamic impairment.

Recently, angiotensin-converting enzyme inhibitors (ACEI) have been prescribed successfully for the treatment of hypertension and congestive heart failure [12]. In addition to normalizing elevated arterial pressure, ACEI treatment improves cardiac output by lowering vascular resistances and also produces renal vasodilatation and natriuresis. Interestingly, these agents have been advocated to prevent deterioration of renal function in hypertensive and diabetic patients [13]. Based on these beneficial effects, and as the RAS is known to be stimulated during aortic abdominal surgery, we hypothesized that ACE inhibition would potentially attenuate systemic haemodynamic and renal functional impairments. Therefore, we tested, in a double-blind randomized study, if a single dose of ACEI administered before operation would preserve systemic oxygen delivery and provide protective renal effects in adult patients undergoing infrarenal aortic surgery.

MARC Licker, MD, Peter NeIDHART, MD (Division of Anaesthesiology); MAREK BeDNarkIEWICZ, MD, RENÉ PRÊTre, MD, MiCHEL MONTESSUTT, MD (Clinics of Cardiovascular Surgery); Hervé Favre, MD (Division of Nephrology); DENIS R. MOREL *, $\mathrm{MD}$ (Division of Anaesthesiological Investigations); University Hospital of Geneva, CH-1211 Geneva 14, Switzerland. Accepted for publication: January 1, 1996.

*Address for correspondence: Division d'Investigations Anesthésiologiques, Hôpital Cantonal Universitaire, CH-1211 Genève 14, Switzerland. 


\section{Patients and methods}

We studied 22 patients undergoing elective infrarenal aortic surgery because of aortic aneurysm or atherosclerotic occlusive disease. Informed consent was obtained and the study was approved by the Committee for Ethics in Clinical Research of our institution. Patients with preoperative renal dysfunction (creatinine clearance $<50 \mathrm{ml} \mathrm{min}^{-1}$ $1.73 \mathrm{~m}^{-2}$ ), cardiac insufficiency (episodes of congestive heart failure or left ventricular ejection fraction $<40 \%$ ), myocardial infarction within the last 6 months, renal artery stenosis detected on the angiogram or those receiving ACEI therapy were excluded.

Usual cardiac medications, except diuretics, were continued up to and including the morning of surgery. Patients were premedicated with midazolam $7.5 \mathrm{mg}$ orally and morphine $0.1 \mathrm{mg} \mathrm{kg}^{-1}$ i.m. In the induction room, radial and thermodilution pulmonary arterial catheters were inserted during local anaesthesia for measurement of mean arterial (MAP), central venous (CVP) and pulmonary capillary wedge pressures (PCWP), and intermittent cardiac output (CO) determination. Electrocardiographic leads II and V5 were attached for monitoring heart rate (HR) and ST changes.

Anaesthesia was induced with alfentanil 30-40 $\mu \mathrm{g}$ $\mathrm{kg}^{-1}$ i.v., given over $1-2 \mathrm{~min}$, followed by thiopentone to loss of the eyelid reflex $\left(3-5 \mathrm{mg} \mathrm{kg}^{-1}\right)$. Neuromuscular block was achieved with pancuronium $0.1 \mathrm{mg} \mathrm{kg}^{-1}$. After tracheal intubation, mechanical ventilation with an air-oxygen mixture was adjusted to maintain arterial blood-gas tensions within the normal range (end-expiratory carbon dioxide fraction $4-4.5 \%$ and arterial oxygen saturation greater than $94 \%$ ). A Foley urinary bladder catheter was inserted after induction of anaesthesia for urinary sampling and urine flow measurement. Throughout the surgical procedure, anaesthesia was maintained with an i.v. infusion of alfentanil 80$120 \mu \mathrm{g} \mathrm{kg}^{-1} \mathrm{~min}^{-1}$ supplemented with inhaled isoflurane (up to $2 \%$ ). Phenylephrine was administered at the discretion of the anaesthetist in order to maintain MAP within a clinically acceptable range (20\% of preoperative values).

Before operation, crystalloids $12 \mathrm{ml} \mathrm{kg}^{-1}$ (containing $\mathrm{Na}^{+} 130 \mathrm{mmol}$ litre ${ }^{-1}, \mathrm{Cl}^{-} 118 \mathrm{mmol}$ litre ${ }^{-1}$ and $\mathrm{K}^{+} 5.4 \mathrm{mmol}$ litre $^{-1}$ ) were infused over $20 \mathrm{~min}$ in all patients. During surgery, fluid loading was titrated to maintain PCWP at $10-15 \mathrm{~mm} \mathrm{Hg}$. Red blood cell concentrates were given when packed cell volume (PCV) decreased to less than $25 \%$. A blood salvage device (Cell Saver 4; Haemonetics Braintree, MA, USA) was used in each case to reduce the need for homologous blood transfusion.

Patients were allocated in a randomized, doubleblind manner to one of two groups: the enalapril group received enalapril $50 \mu \mathrm{g} \mathrm{kg}^{-1}$ (Reniten, Merck, Sharp \& Dohme Research Laboratories, NJ, USA) diluted in $20 \mathrm{ml}$ of normal saline and injected i.v. over $5 \mathrm{~min}(n=12)$; the saline group received the same volume of saline solution $(n=10)$. In a dosefinding study, conducted in similar surgical patients, we demonstrated that a single $50-\mu \mathrm{g} \mathrm{kg}^{-1}$ i.v. in- jection given before surgery produced marked inhibition $(>90 \%)$ of plasma angiotensin-converting enzyme activity for more than $20 \mathrm{~h}$ whereas lower doses (10 and $30 \mu \mathrm{g} \mathrm{kg}^{-1}$ ) produced ACE inhibition of shorter duration (90\% ACE inhibition up to 4 and $8 \mathrm{~h}$ after administration of enalapril 10 and $30 \mu \mathrm{g}$ $\mathrm{kg}^{-1}$, respectively). The drugs were given $25 \mathrm{~min}$ before induction of anaesthesia, when a stable basal systemic haemodynamic state had been reached and while patients were fluid loaded with i.v. crystalloids. The subsequent changes in haemodynamic state, oxygen uptake and renal function were assessed in the two groups before and during aortic crossclamping and after aortic unclamping.

Blood temperature and cardiac output, determined in triplicate by injection of $10 \mathrm{ml}$ of $5 \%$ glucose solution, were measured by a cardiac output computer (Model 9520A, American Edwards Laboratories, Irvine, CA, USA). Systemic haemodynamic data (HR, MAP, CVP, PCWP, CO) were recorded at end-expiration at the following times: (1) before anaesthesia (i.e. before and $20 \mathrm{~min}$ after administration of drug), (2) during the surgical aortic approach (i.e. $2 \mathrm{~min}$ after skin incision, and $2 \mathrm{~min}$ before aortic cross-clamping), (3) during aortic cross-clamping (i.e. 5 min after aortic cross-clamping and immediately before ilio-femoral unclamping) and (4) after vascular unclamping (i.e. 2 min after "first leg" unclamping, and during peritoneal closure). Systemic vascular resistance index (SVRI) and cardiac index (CI) were calculated according to standard formulae.

Glomerular filtration rate (GFR) and effective renal plasma flow (ERPF) were estimated using a constant infusion technique of inulin and paraaminohippuric acid (PAH). Priming doses of inulin $30 \mathrm{mg} \mathrm{kg}^{-1}$ (10\% Inulin; Laevosan $\mathrm{GmbH}$, Linz, Austria) and PAH $8 \mathrm{mg} \mathrm{kg}^{-1}$ (Merck, Sharp \& Dohme, NJ, USA) were given i.v. followed by a continuous infusion of both drugs at doses of $0.20 \mathrm{mg} \mathrm{kg}^{-1} \mathrm{~min}^{-1}$ and $0.15 \mathrm{mg} \mathrm{kg}^{-1} \mathrm{~min}^{-1}$, respectively. After an 80-min equilibration period, urine was collected over at least $30 \mathrm{~min}$ before (preclamping) and during aortic cross-clamping (clamping), and after "first leg" reperfusion (post-clamping); arterial blood was sampled in the middle of each collection period. Urinary and plasma inulin and PAH concentrations were assayed spectrophotometrically. Inulin and $\mathrm{PAH}$ clearances $\left(C_{\mathrm{IN}}, C_{\mathrm{PAH}}\right)$ were calculated as the respective urine concentration divided by arterial plasma concentration multiplied by urine volume in $\mathrm{ml} \mathrm{min}^{-1}$; these data were corrected for standard body surface area $\left(1.73 \mathrm{~m}^{2}\right)$. As PAH handling within the kidney is altered during surgery and anaesthesia, the renal extraction fraction of $\mathrm{PAH}\left(E_{\mathrm{PAH}}=\right.$ arterial - venous plasma concentration divided by arterial concentration of PAH) was determined. Therefore, the surgeon directly punctured the renal vein and slowly withdrew venous blood as close to the kidney as possible. A "corrected" ERPF was obtained (ERPF = $\left.C_{\mathrm{PAH}} / E_{\mathrm{PAH}}\right)$ and $\mathrm{RBF}$ was calculated as: $\mathrm{RBF}=$ $\mathrm{ERPF} \times 100 /(100-\mathrm{PCV})$. During the pre-clamping, aortic clamping and post-clamping periods, systemic haemodynamic variables (MAP, CVP, CO) were 
averaged as the mean of three measurements obtained 15 min apart at the beginning, middle and end of urine sampling. Renal vascular resistance (RVR) and fractional renal blood flow (RBF) were calculated using the following equations: $\mathrm{RVR}=(\mathrm{MAP}-\mathrm{CVP}) / \mathrm{RBF} \times 79.9$ and fractional $\mathrm{RBF}=\mathrm{RBF} / \mathrm{CO} \times 100$.

Additional renal functional tests comprised calculation of creatinine clearance ( $\left.C_{\text {Creat }}\right)$, fractional sodium excretion $\left(F_{\mathrm{E}_{\mathrm{Na}^{+}}}\right)$, total sodium excretion $\left(U_{\mathrm{Na}^{+}}\right)$and protein excretion. $F \mathrm{E}_{\mathrm{Na}^{+}}$was calculated by dividing the urine-to-plasma sodium ratio by the urine-to-plasma creatinine ratio times 100; $U_{\mathrm{Na}^{+}}$ equals the product of urinary sodium and urinary flow. Proteinuria and $C_{\text {Creat }}$ were also assessed on the day before surgery and $12 \mathrm{~h}$ after operation (12-h urine collection period). Serum and urinary sodium and creatinine concentrations were measured with a standard flame emission photometer. Diuretics, mannitol and dopamine were not given during the entire study.

In arterial and mixed venous blood samples, haemoglobin $(\mathrm{Hb})$, oxygen tension and oxygen saturation $\left(\mathrm{Sa}_{\mathrm{O}_{2}}, S \overline{\mathrm{v}}_{\mathrm{O}_{2}}\right)$ were measured directly (ABL Radiometer OSM3, Copenhagen, Denmark). Total body oxygen consumption $\left(\dot{V}_{\mathrm{O}_{2}}\right)$ was estimated as the product of $\mathrm{CO}$ and the arteriovenous oxygen content difference. Total body oxygen delivery $\left(\mathrm{Do}_{2}\right)$ was derived as $\mathrm{CO} \times$ arterial oxygen content.

\section{STATISTICAL ANALYSIS}

All data are expressed as mean (SD). The influence of enalapril treatment was tested by the Mann-Whitney two-sample test. To determine if differences existed between times, repeated measures analysis of variance was performed followed by the two-tailed paired Student's $t$ test and Dunnett's correction for multiple comparisons. Regression analyses between changes in systemic and renal haemodynamic state and renal functional variables in response to aortic clamping and after aortic unclamping were analysed within each group. Correlations were also determined between inulin and creatinine clearance and between changes in $\mathrm{Do}_{2}$ and $\dot{\mathrm{V}}_{2}$. For all statistical comparisons, significance was defined as $P<0.05$.

\section{Results}

Two patients (one in each group) were excluded from the study because the surgeon had to proceed with vascular clamping involving one (or both) renal artery(ies). Therefore, there were nine and 11 patients in the saline and enalapril groups, respectively. There were no differences between the two groups in preoperative clinical characteristics and surgical management (table 1). All patients (except one in the saline group) were treated with either $\beta$-blockers, calcium-channel blockers, diuretics or a combination of these drugs. Preoperative creatinine clearance was within the normal range in both groups. Intraoperative fluid requirements tended to be slightly greater in the enalapril group compared with the saline group, but this was not statistically significant for red cell transfusion and crystalloid infusion.
SYSTEMIC HAEMODYNAMIC AND METABOLIC DATA

(fig. 1, table 2)

Before anaesthesia and after fluid loading, enalapril $50 \mu \mathrm{g}$ induced increases in CI $(+12 \% ; P=0.023)$ and $\mathrm{DO}_{2}$ and decreases in SVRI, without changes in MAP and HR. In the saline group, CI tended to increase, although this was not significant $(+7 \%)$. General anaesthesia was associated with similar decreases in $\dot{V}_{\mathrm{O}_{2}}$ in the two groups $(-19 \%$ in the

Table 1 Patient characteristics and operative data (mean (SD or range) or number). No significant difference between the two groups

\begin{tabular}{|c|c|c|}
\hline & $\begin{array}{l}\text { Saline group } \\
(n=9)\end{array}$ & $\begin{array}{l}\text { Enalapril } \\
\text { group } \\
(n=11)\end{array}$ \\
\hline \multicolumn{3}{|l|}{ Patient characteristics } \\
\hline Age (yr) & $68(53-79)$ & $69(55-81)$ \\
\hline $\operatorname{Sex}(M / F)$ & $7 / 2$ & $10 / 1$ \\
\hline Body surface area $\left(\mathrm{m}^{2}\right)$ & $1.74(0.21)$ & $1.82(0.11)$ \\
\hline Aortic aneurysm $(n)$ & 2 & 2 \\
\hline Hypertensive disease $(n)$ & 8 & 10 \\
\hline Coronary artery disease $(n)$ & 3 & 4 \\
\hline $\begin{array}{l}\text { History of pulmonary } \\
\text { oedema }(n)\end{array}$ & 1 & 0 \\
\hline $\begin{array}{l}\text { Creatinine clearance } \\
\left(\mathrm{ml} \mathrm{min}^{-1} 1.73 \mathrm{~m}^{-2}\right)\end{array}$ & $87(21)$ & $77(19)$ \\
\hline \multicolumn{3}{|l|}{ Preoperative drug therapy } \\
\hline$\beta$ blockers $(n)$ & 5 & 5 \\
\hline $\mathrm{Ca}^{2+}$-channel blockers $(n)$ & 3 & 5 \\
\hline Diuretics $(n)$ & 1 & 2 \\
\hline \multicolumn{3}{|l|}{ Intraoperative data } \\
\hline $\begin{array}{l}\text { Cross-clamping time } \\
\text { (min) }\end{array}$ & $69(26)$ & $74(23)$ \\
\hline $\begin{array}{l}\text { Duration of surgery } \\
\text { (min) }\end{array}$ & $300(78)$ & $292(46)$ \\
\hline Packed red cells (ml) & $311(314)$ & $487(413)$ \\
\hline Crystalloids (litre $\mathrm{h}^{-1}$ ) & $1.76(0.21)$ & $1.97(0.45)$ \\
\hline
\end{tabular}

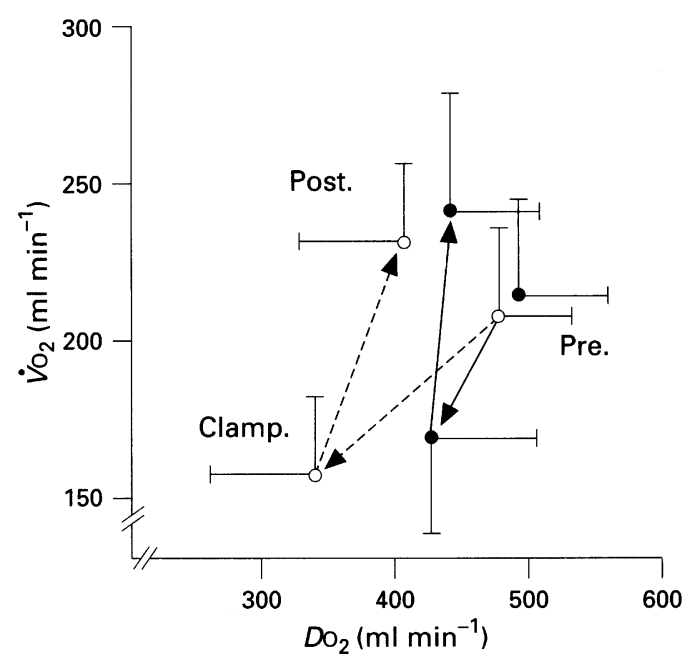

Figure 1 Changes in systemic oxygen delivery $\left(D_{2}\right)$ and oxygen consumption $\left(\dot{V}_{\mathrm{O}_{2}}\right)$ in the saline $(\mathrm{O})$ and enalapril (O) groups. Data represent mean (SD) values of averaged $\mathrm{DO}_{2}$ and $\dot{V}_{\mathrm{O}_{2}}$ measured before (Pre.) (2 min after incision and $2 \mathrm{~min}$ before aortic cross-clamping), during (clamp.) (5 min after aortic clamping and before aortic unclamping) and after (Post.) 2 min after unclamping and at peritoneal closure) aortic crossclamping. 


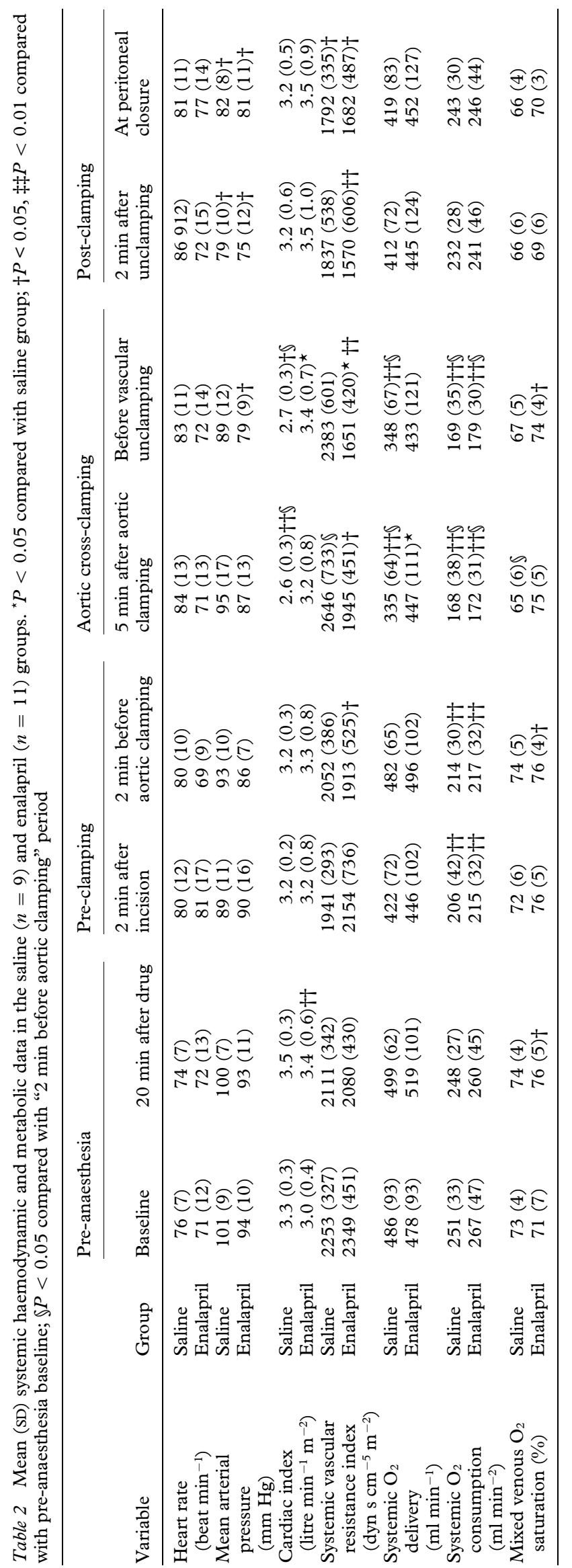



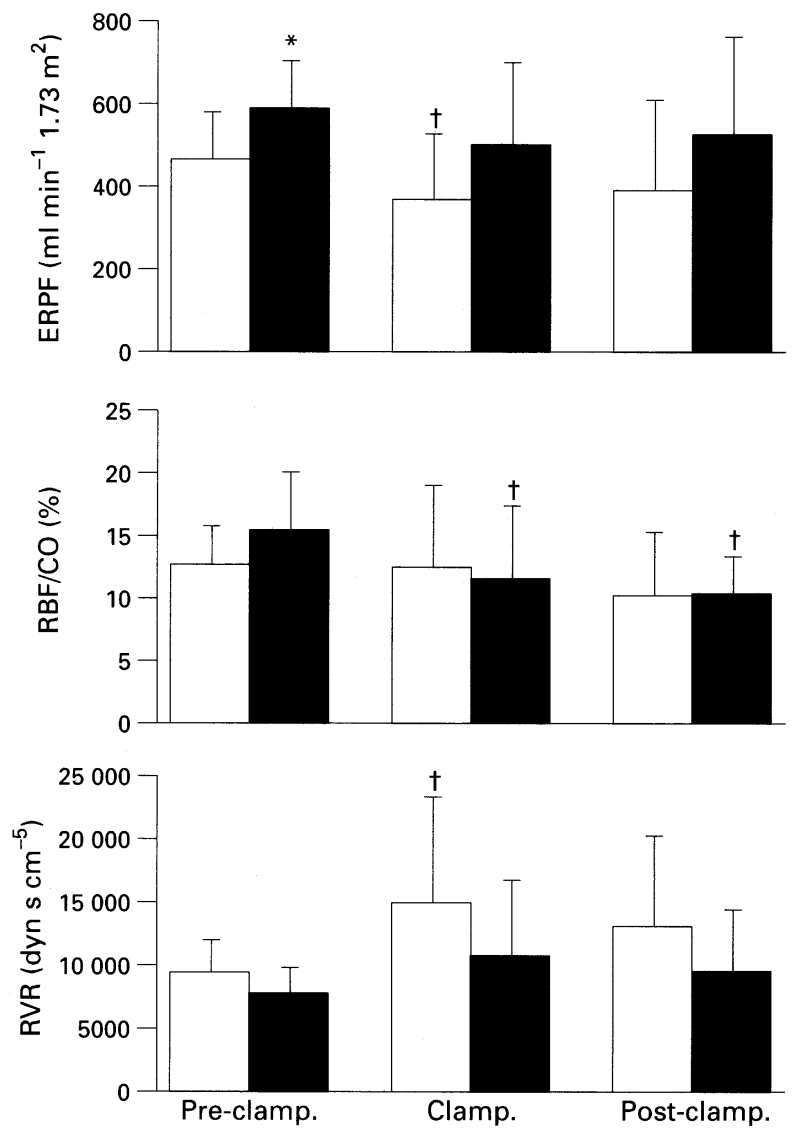

Figure 2 Effective renal plasma flow (ERPF), fractional renal blood flow (\% RBF/CO) and renal vascular resistance (RVR) at the pre-clamping, clamping and post-clamping periods, in the saline $(\square)$ and enalapril $(\square)$ groups. ${ }^{\star} P<0.05$ compared with saline group; $\dagger P<0.05$ compared with pre-clamping.

saline group and $-6 \%$ in the enalapril group). Two patients in the enalapril group and one in the saline group required an i.v. bolus of phenylephrine $100 \mu \mathrm{g}$ after induction of anaesthesia.

There was no significant difference in HR or MAP between the two groups at any time. Towards the end of surgery, MAP and SVRI were decreased significantly in the two groups, compared with preanaesthesia baseline values.
In the saline group, aortic cross-clamping induced a decrease in CI $(-29 \% ; P=0.001)$; the associated reduction in $\mathrm{DO}_{2}(-28 \%)$ correlated with the reduction in $\dot{V}_{\mathrm{O}_{2}}(-24 \% ; P<0.001 ; r=0.85)$ and was accompanied by decreased oxygen saturation in mixed venous blood $\left(S \overline{\mathrm{v}}_{\mathrm{O}_{2}},-9 \% ; P=0.030\right)$. In contrast, in the enalapril group, CI was maintained at pre-clamping values and the reduction in $\dot{V}_{\mathrm{O}_{2}}$ $-20 \% ; P<0.001)$ induced by aortic cross clamping was not associated with significant changes in $\mathrm{DO}_{2}$ or $S \overline{\mathrm{v}}_{\mathrm{O}_{2}}$. After aortic unclamping, $\dot{\mathrm{V}}_{2}$ increased to pre-clamping values in the two groups; this was accompanied by a significant increase in $\mathrm{Do}_{2}$ in the saline group only $(+19 \% ; P=0.034)$.

\section{RENAL HAEMODYNAMIC VARIABLES AND FUNCTION}

(fig. 2, table 3)

During the pre-clamping period, in enalapril-treated patients, $C_{\text {Creat }}$ was increased compared with the preoperative period $(+27 \% ; P=0.035)$ and higher ERPF values were noted compared with salinetreated patients $(P=0.027)$.

In the saline group, aortic cross-clamping was associated with significant decreases in $C_{\text {Creat }}, C_{\mathrm{IN}}$ and ERPF, whereas the fraction of $\mathrm{CO}$ (RBF/CO ratio) delivered to the kidney did not change. In the enalapril group, after aortic cross-clamping, the $\mathrm{RBF} / \mathrm{CO}$ ratio decreased significantly and GFR was greater than in the saline group, as indicated by $C_{\text {Creat }}$ (78 (28) vs 53 (17) $\mathrm{ml} \mathrm{min}^{-1} 1.73 \mathrm{~m}^{-2} ; P=0.052$ )

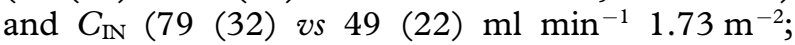
$P=0.033)$. The simultaneous changes in systemic and renal haemodynamic variables resulted in unchanged RVR in the enalapril group whereas renal vasoconstriction occurred in the saline group, as indicated by increases in RVR $(P=0.044)$. In both groups, a positive linear relationship was found between aortic clamping-induced changes in ERPF and GFR ( $r=0.83$ in the saline group and $r=0.65$ in the enalapril group). No such relationship was found between CI and ERPF and between CI and GFR.

After vascular unclamping and until $24 \mathrm{~h}$ after surgery, $C_{\text {Creat }}$ values in the saline group remained

Table 3 Mean (SD) renal functional data in the saline $(n=9)$ and enalapril $(n=11)$ groups. ${ }^{\star} P<0.05$ compared with saline group; $\dagger P<0.05, \dagger \dagger P<0.01$ compared with preoperative period; $₫ P<0.05$ compared with preclamping period

\begin{tabular}{|c|c|c|c|c|c|c|}
\hline \multirow[b]{2}{*}{ Variable } & \multirow[b]{2}{*}{ Group } & \multirow[b]{2}{*}{ Preoperative } & \multicolumn{3}{|l|}{ Surgery } & \multirow[b]{2}{*}{ Postoperative } \\
\hline & & & Pre-clamping & $\begin{array}{l}\text { Aortic } \\
\text { clamping }\end{array}$ & Post-clamping & \\
\hline \multirow{2}{*}{ 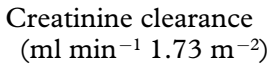 } & Saline & $87(21)$ & $76(34)$ & $53(17)+5$ & $59(26)+\delta$ & $64(22) \dagger$ \\
\hline & Enalapril & 77 (19) & $97(28) \dagger$ & $78(28) \sqrt{ }$ & $80(33)$ & $88(23) \dagger$ \\
\hline \multirow{2}{*}{$\begin{array}{l}\text { Urinary flow } \\
\left(\mathrm{ml} \mathrm{min}^{-1}\right)\end{array}$} & Saline & $0.7(0.3)$ & $1.8(1.0)$ & $1.2(0.6)$ & $2.1(2.4) \dagger$ & $1.5(0.3) \dagger$ \\
\hline & Enalapril & $0.8(0.3)$ & $3.0(1.8) \dagger$ & $3.6(2.1) \dagger$ & $3.7(2.3) \dagger$ & $1.6(0.6) \mathrm{t \dagger}$ \\
\hline \multirow{2}{*}{$\begin{array}{l}\text { Free water clearance } \\
\quad\left(\mathrm{ml} \mathrm{min}^{-1}\right)\end{array}$} & Saline & $-0.8(0.2)$ & $-0.2(0.8)$ & $-0.3(0.3) \dagger$ & $-0.6(0.8)$ & $-0.6(0.2)$ \\
\hline & Enalapril & $-0.9(0.2)$ & $-1.1(1.0)$ & $-1.0(0.7)$ & $-0.8(1.0)$ & $-1.0(0.9)$ \\
\hline \multirow{2}{*}{$\begin{array}{l}\text { Proteinuria } \\
\left(\mathrm{mg} \mathrm{min}^{-1}\right)\end{array}$} & Saline & $0.08(0.05)$ & $0.61(0.50) \dagger$ & $1.19(1.06) \dagger$ & $2.42(2.54) \dagger$ & $1.08(0.98) \dagger$ \\
\hline & Enalapril & $0.12(0.05)$ & $1.10(1.03) \dagger$ & $1.29(1.98) \dagger$ & $3.12(4.21) \dagger$ & $1.44(1.32) \dagger$ \\
\hline \multirow{2}{*}{$\begin{array}{l}\mathrm{Na}^{+} \text {fractional } \\
\text { excretion }(\%)\end{array}$} & Saline & $0.3(0.2)$ & $2.4(1.2)+\dagger$ & $2.4(1.1) \dagger \dagger$ & $3.4(2.1)+\dagger$ & $2.4(1.6)+\dagger$ \\
\hline & Enalapril & $0.4(0.2)$ & $3.1(2.1) \mathrm{t \dagger}$ & $3.7(3.4) \mathrm{t \dagger}$ & $4.3(3.3) \mathrm{t \dagger}$ & $1.7(1.2) \dagger+$ \\
\hline \multirow{2}{*}{$\begin{array}{l}\mathrm{Na}^{+} \text {urinary } \\
\text { excretion } \\
(\mu \mathrm{Eq} / \mathrm{min})\end{array}$} & Saline & $39(30)$ & $207(121) \dagger$ & $145(90) \dagger$ & $245(125) \dagger$ & $163(63) \dagger$ \\
\hline & Enalapril & $44(33)$ & 400 (135) t† & 453 (201) t† & 502 (375) t† & $173(90) \dagger$ \\
\hline
\end{tabular}


significantly lower than during the preoperative period. In contrast, in the enalapril group, $C_{\text {Creat }}$ did not differ from preoperative values, and postoperative $C_{\text {Creat }}$ was significantly higher than in the saline group. During operation, urinary output was comparable, whereas $F_{\mathrm{E}_{\mathrm{Na}^{+}}}, U_{\mathrm{Na}^{+}}$and proteinuria were significantly increased compared with preoperative values in the two groups.

We found a close correlation between $C_{\mathrm{IN}}$ and $C_{\text {Creat }}(r=0.89 ; n=59 ; P<0.001)$ and no significant change in $E_{\mathrm{PAH}}$ at the three intraoperative study times.

All patients survived the operation; the trachea was extubated in the operating theatre and they were monitored in a post-anaesthesia recovery unit for $24 \mathrm{~h}$. No patient had ECG evidence of myocardial infarction and no episode of delayed renal failure occurred until discharge from hospital in the two groups.

\section{Discussion}

In this study we have demonstrated that preoperative administration of enalapril, a long-acting ACEI, prevented the decrease in $\mathrm{CI}$ and $\mathrm{DO}_{2}$ induced by infrarenal aortic cross-clamping, without influencing changes in oxygen uptake. Acute RAS block is associated with improved intraoperative renal perfusion and better preservation of GFR, lasting at least $24 \mathrm{~h}$ after surgery.

We administered enalapril in an unusually high dose $\left(50 \mu \mathrm{g} \mathrm{kg}^{-1}\right)$ with the aim of inhibiting plasma ACE activity, and hence angiotensin II synthesis, for at least $24 \mathrm{~h}$. Indeed, elevated PRA has been reported after surgical incision and increased angiotensin II plasma concentrations are known to culminate at the time of unclamping and to persist for more than $6 \mathrm{~h}$ after operation $[9,10,14]$. We also found that lower enalapril doses (10 and $30 \mu \mathrm{g} \mathrm{kg}^{-1}$ ) did not afford suppression of plasma ACE activity for the whole perioperative period.

Acute removal of angiotensin II vasopressor effects could potentially contribute to intraoperative hypotension because of synergistic effects between ACEI and other chronic antihypertensive drugs given before operation. Surprisingly, acute block of the RAS was associated with a stable haemodynamic state and there were no differences in vasopressor and fluid requirements between the two groups. We believe that haemodynamic tolerance to enalapril pretreatment was attributed to optimal i.v. fluid loading. In addition, the other arterial pressure regulating mechanisms (the sympathetic nervous system and arginine vasopressin), were either unaffected or blocked incompletely; hence, these mechanisms were presumably activated after surgical incision, to maintain arterial pressure homeostasis after withdrawal of the vasoconstricting influence of angiotensin II [15].

In accordance with previous investigations [16], we observed a marked decrease in CO $(-29 \%)$ despite stable arterial and cardiac filling pressures after exclusion of the lower body compartment in saline-treated patients. Several physiological mechanisms are thought to be implicated in the haemo- dynamic changes associated with aortic cross-clamping. First, mechanical occlusion of the aorta directly increases cardiac afterload whereas activation of the sympathetic nervous system and the RAS results in increased arteriolar vasomotor tone and myocardial contractility. Second, using radioisotopic techniques, it has been shown that blood volume is redistributed from the lower body to the more compliant splanchnic compartment [17]. Third, decreased right ventricular end-diastolic volume has been reported, despite unchanged cardiac filling pressures, suggesting lower cardiac preload associated with reduced ventricular diastolic compliance [18]. Taken together these data suggest that the reduction in $\mathrm{CO}$ results mainly from reduced blood flow return to the heart (partly attributed to the slower time constant of blood flow within the splanchnic compartment) combined with a sudden increase in impedance to blood flow as a result of mechanical aortic occlusion and arteriolar vasoconstriction. Interestingly, several studies have demonstrated less haemodynamic changes after aortic cross-clamping in patients with aorto-occlusive disease than in those with abdominal aortic aneurysm. It is currently believed that the amount of collateral vascularization in patients with aorta-occlusive disease could afford some protection against major reductions in $\mathrm{CO}$ and increases in arterial pressure after aortic cross-clamping [19].

An important finding of this study was that enalapril pretreatment prevented the decrease in cardiac output induced by aortic cross-clamping. Experimental data suggest that the splanchnic vascular bed is extremely sensitive to vasoconstrictor agents, including catecholamines and angiotensin II, particularly during pathological conditions such as hypovolaemia or cardiac failure [20-22]. Acute administration of ACEI in dogs with congestive heart failure has also been shown to increase the unstressed splanchnic vascular volume and to improve circulatory output by promoting active vasodilatation [23]. Based on these results, we speculate that block of the RAS prevented the reduction in CI by alleviating elevated angiotensin II-dependent vascular impedance and hence by promoting "adaptive" splanchnic vasodilatation to accommodate for the sudden shift in blood volume from the lower to the upper body compartment. Other vasodilatators such as nifedipine [24], urapidil [25] and nitroglycerine [26] were also found to reverse the decrease in cardiac output induced by cross-clamping; however, in contrast with ACEI, they are associated with increased sympathetic discharge, that may affect the extent and pattern of changes in blood volume redistribution and in haemodynamic response.

Although pretreatment with enalapril produced maintenance of $\mathrm{CI}$ and $\mathrm{Do}_{2}, \dot{\mathrm{V}}_{2}$ decreased similarly during infrarenal clamping in the two groups. Gelman and co-workers [25] reported similar results when nitroglycerine was infused at a rate of 1 to $2 \mu \mathrm{g}$ $\mathrm{kg}^{-1} \mathrm{~min}^{-1}$ in order to maintain cardiac output. As whole body oxygen utilization was not restored after the pharmacologically induced increase in $\mathrm{Do}_{2}$, we assume that maximal vasorelaxation had already occurred in ischaemic tissues located below the 
aortic clamp (in response to local vasodilators) and that enalapril (and nitroglycerine) increased shunt blood flow in the upper body compartment with no improvement in nutritive flow or tissue oxygen extraction, or both. Hence, systemic oxygen supply was matched adequately to the cross-clamp "adapted $\dot{\mathrm{V}} \mathrm{O}_{2}$ " in the saline group whereas "unnecessary" elevated oxygen supply and myocardial work were achieved during aortic cross-clamping in the enalapril group.

Considering the stimulatory effects of surgical stress on the RAS and the potent renal vasoconstrictor effects of angiotensin II, it was not surprising to find that suppression of circulating and, presumably, intrarenal angiotensin II generation in enalapril-treated patients was associated with higher ERPF (a mean difference of $17 \%$ ) compared with saline-treated patients. Animal studies have demonstrated that enhanced renal blood flow was the most impressive regional haemodynamic change after administration of different types of ACEI [26]; blood flow within the inner cortex was predominantly increased and accompanied by enhanced GFR [27]. The renal haemodynamic actions of ACEI have at least two components: suppression of angiotensin II synthesis and prolongation of bradykinin half-life through inhibition of its degradation. This latter component is thought to mediate renal vasodilatation even when RAS activation is prevented by preoperative $\beta$ blocker treatment [28], as renin secretion from the juxtaglomerular cells is dependent on $\beta_{1}$ receptor stimulation.

Before aortic cross-clamping, ACEI-treated patients had higher GFR compared with salinetreated patients, because of higher ERPF as increased cortical blood flow would transform "silent" nephrons into new filtering units. During aortic cross-clamping, a reduction in GFR occurred in both groups and the changes in GFR correlated positively with changes in ERPF, indicating that the neurohumoral mediators that regulate renal haemodynamic state ultimately influence glomerular filtration properties. Deterioration of systemic haemodynamic state and release of vasoconstrictor mediators such as angiotensin II, thromboxane $\mathrm{A}_{2}$ and endothelin-1 after aortic cross-clamping are believed to contribute to impaired renal function [29]. In this study, maintenance of GFR in enalapril-treated patients could be attributed to a lesser decrease in ERPF or to an increase in the glomerular ultrafiltration coefficient as a consequence of the withdrawal of the constricting effects of angiotensin II on mesangial cells, or both. Endothelin-1 has several additional synergistic interactions with the RAS, including enhanced ACE activity (conversion of angiotensin I to angiotensin II), potentiation of endothelin constriction by angiotensin II and activation of endothelin-1 synthesis by angiotensin II. The clinical importance of these interactions has recently been emphasized by demonstration that ACEI pretreatment abolishes renal vasoconstriction and the decrease in GFR induced by endothelin-1 [30].

In the saline group, GFR remained depressed after aortic unclamping, at a time when CI had recovered to pre-clamping values. Adenosine and oxygen-derived free radicals liberated from the ischaemic reperfused tissues are potential candidates for this transient renal dysfunction. Adenosine requires a normally functioning RAS to mediate its pre-glomerular vasoconstrictor action and administration of an ACEI has been shown to attenuate adenosine-mediated vasoconstriction [31]. Colson and co-workers [32] studied patients who received enalapril $10 \mathrm{mg}$ orally, for 2 days before undergoing vascular surgery during i.v. anaesthesia. In agreement with our results, they found lesser haemodynamic changes induced by aortic cross-clamping in the treated group. However, there was no positive effect on renal haemodynamic state or function, as assessed from clearance of ${ }^{99}$ technetium-diethylenetriaminepenta-acetic acid and ${ }^{131}$ iodo-hippuran, respectively. Differences in dose regimen, anaesthetic management and measurements methods could account for these contradictory results.

In summary, we have demonstrated that a single i.v. dose of enalapril can be administered safely in patients undergoing elective abdominal aortic surgery when optimal fluid loading is maintained. This pretreatment is associated with suppression of the aortic clamping-induced reduction in cardiac output, renal vasodilatation and better preservation of glomerular filtration. Oxygen consumption decreased markedly after aortic-clamping, despite ACEI-induced maintenance of systemic oxygen supply. The renoprotective effect of enalapril could be attributed to withdrawal of the constricting action of angiotensin II, reduced kinin degradation and antagonism of endothelin-1. These effects would also be potentially helpful in patients undergoing suprarenal aortic cross-clamping or kidney transplantation. However, it should be kept in mind that ACE inhibitors could precipitate onset of renal failure in hypovolaemic subjects or in the presence of renal artery stenosis. Before suggesting specific indications, further studies are needed to define in which population subgroups RAS block may be beneficial.

\section{References}

1. Gelman S. The pathophysiology of aortic cross-clamping and unclamping. Anesthesiology 1995; 82: 1026-1060.

2. Gamulin Z, Forster A, Morel DR, Simonet F, Aymon E, Favre H. Effects of aortic cross-clamping on renal hemodynamics in humans. Anesthesiology 1984; 61: 394-399.

3. Paul MD, Mazer CD, Byrick RJ, Rose DK, Goldstein MB. Influence of mannitol and dopamine on renal function during elective infrarenal aortic clamping in man. American foumal of Nephrology 1986; 6: 427-434.

4. Gamulin Z, Forster A, Simonet F, Aymon E, Favre H Effects of renal sympathetic blockade on renal hemodynamics in patients undergoing major aortic abdominal surgery. Anesthesiology 1986; 65: 688-692.

5. Huval WV, Lelcuk S, Allen PD, Mannick JA, Shepro D, Hechtman HB. Determinants of cardiovascular stability during abdominal aortic aneurysmectomy (AAA). Annals of Surgery 1984; 199: 216-222.

6. Casthely PA, Diunezki, J, Jones R, Goodman K, Redko V, Cottrell JE, Yoganathan T, Fiordalisi J. Superoxide dismutase and hemodynamic changes following aortic cross clamp release. Fournal of Cardiothoracic Anesthesia 988; 2: 450-454.

7. Antonucci F, Bertolissi M, Calo L. Plasma endothelin and renal function during infrarenal aortic cross-clamping and nifedipine infusion. Lancet 1990; 336: 1449. 
8. Mirenda JV, Grissom TE. Anesthetic implications of the renin-angiotensin system and angiotensin-converting enzyme inhibitors. Anesthesia and Analgesia 1991; 72: 667-683.

9. Dzau VJ. Tissue renin-angiotensin system: Physiologic and pharmacologic implications. Circulation 1988; 77(Suppl. 1): $1-3$.

10. Gal TJ, Cooperman LH, Berkowitz HD. Plasma renin activity in patients undergoing surgery of the abdominal aorta. Annals of Surgery 1974; 178: 65-69.

11. Grindlinger GA, Vegas AM, Manny J, Bush HL, Mannick JA, Hechtman HB. Volume loading and vasodilators in abdominal aortic aneurysmectomy. American fournal of Surgery 1980; 139: 480-486.

12. Kostis JB. Angiotensin-converting enzyme inhibitors. II. Clinical use. American Heart fournal 1988; 116: 1591-1605.

13. Hollenberg NK, Raij L. Angiotensin-converting enzyme inhibition and renal protection. An assessment of implications for therapy. Archives of Internal Medicine 1993; 153: 2426-2435.

14. Grindlinger GA, Vegas AM, Williams GH, Mannick JA, Hechtman HB. Independence of renin production and hypertension in abdominal aortic aneurysmectomy. American Fournal of Surgery 1981; 141: 475-477.

15. Udelsman R, Norton JA, Jelenich SE, Goldstein DS, Linehan WM, Loriaux DL, Chrousos GP. Response of the hypothalamic-pituitary adrenal and renin-angiotensin axes and the sympathetic system during controlled surgical and anesthetic stress. Fournal of Clinical Endocrinology and Metabolism 1987; 64: 986-994.

16. Falk JL, Rackow EC, Blumenberg R, Gelfand M, Fein IA. Hemodynamic and metabolic effects of abdominal aortic crossclamping. American fournal of Surgery 1981; 142: 174-177.

17. Gelman S, Khazaeli MB, Orr R, Henderson T. Blood volume redistribution during crossclamping of the descending aorta. Anesthesia and Analgesia 1994; 78: 219-224.

18. Vandermeer TJ, Maini BS, Hendershott TH, Sottile FD. Evaluation of right ventricular function during aortic surgery. Archives of Surgery 1993; 128: 582-585.

19. Johnston WE, Balestrieri FJ, Plonk G, D'Souza V, Howard G. The influence of periaortic collateral vessels on the intraoperative hemodynamic effects of acute aortic occlusion in patients with aorto-occlusive disease or abdominal aortic aneurysm. Anesthesiology 1987; 66: 386-389.

20. Reilly PM, Bulkley GB. Vasoactive mediators and splanchnic perfusion. Critical Care Medicine 1993; 21(Suppl. 1): S55S68.
21. Stockland O, Thorvaldsen A, Ilebekk A, Kiil F. Mechanisms of blood pressure elevation during angiotensin infusion. Acta Physiologica Scandinavica 1982; 15: 455-465.

22. Risoe C, Hall C, Smiseth OA. Effect of enalaprilat on splanchnic vascular capacitance during acute ischemic heart failure in dogs. American Foumal of Physiology 1994; 266: H2182-H2189.

23. Derrer SA, Bastulli JA, Baele H, Rhodes RS, Dauchot PJ. Effects of nifedipine on the hemodynamic response to clamping and declamping of the abdominal aorta in dogs. Fournal of Cardiothoracic Anesthesia 1989; 3: 58-64.

24. Van Hemelrijk J, Waets P, Van Aken H, Lacroix H, Nevelsteen A, Suy R. Blood pressure management during aortic surgery: urapidil compared to isosorbide dinitrate. Fournal of Cardiothoracic Anesthesia 1993; 7: 273-278.

25. Gelman S, McDowell H, Varner PD, Pearson J, Ebert J, Graybar G, Proctor J. The reasons for cardiac output reduction after aortic cross-clamping. American fournal of Surgery 1988; 155: 578-586.

26. Richer C, Dousseau M-P, Giuducelli JF. Systemic and regional hemodynamic profile of five angiotensin I converting enzyme inhibitors in the spontaneously hypertensive rat. American fournal of Cardiology 1987; 59: 12D-17D.

27. Noguchi K, Ojiri Y, Chibana T, Sakanashi M. Simultaneous measurement of renal blood flow of the outer and inner cortex by laser-Doppler flowmetry in anesthetized dogs: Effects of enalapril diacid. Archives Internationales de Pharmacodynamie et de Therapie 1992; 320: 68-80.

28. Grant RP, Jenkins LC. Modification by preoperative betablockade of the renin response to infrarenal aortic crossclamping. Canadian Anaesthesia Society fournal 1983; 30: 480-486.

29. Apperloo AJ, de Zeeuw D, de Jong PE. Discordant effects of enalapril and lisinopril on systemic and renal hemodynamics. Clinical Pharmacology and Therapeutics 1994; 56: 647-658.

30. Chan DP, Clavell A, Keiser J, Burnett JC. Effects of renin-angiotensin system in mediating endothelin-induced renal vasoconstriction; therapeutic implications. Fournal of Hypertension 1994; 12: S43-S49.

31. Hall JE, Granger JP, Hester RL. Interaction between adenosine and angiotensin II in controlling glomerular filtration. American foumal of Physiology 1985; 248: F340F346.

32. Colson P, Ribstein J, Seguin JR, Marty-Ane C, Roquefeuil B. Mechanisms of renal hemodynamic impairment during infrarenal aortic cross-clamping. Anesthesia and Analgesia 1992; 75: 18-23. 